\title{
Waste-to-energy application in an industrial district
}

\author{
Antonella Meneghetti*, Gioacchino Nardin, Patrizia Simeoni \\ DiEM, Dipartimento di Energetica e Macchine, University of Udine, Via delle Scienze 208, \\ 33100 Udine, Italy
}

Received 29 March 2001; received in revised form 26 November 2001; accepted 2 December 2001

\begin{abstract}
Industrial districts present some features that can be recognized and exploited in the plant engineering through the proposal of solutions which are not simple applications of models created for individual companies. This work illustrates a waste-to-energy plant to be used for the industrial waste of the district of Friuli Venezia Giulia. The project from the union between university and local entrepreneurs. It is described how the expense for woodworkingwaste disposal can turn from a charge into an advantage for the firms of the district thanks to the incineration of this waste in a plant unique for the typology of waste treated. Each plant section is described in detail, underlining innovative approaches and solutions. (C) 2002 Elsevier Science Ltd. All rights reserved.
\end{abstract}

\section{Introduction}

The industrial districts, made up of many middle-small sized companies, located in a well-defined area and specialized in the manufacture of one product or in a productive process, represent one of the characteristic and most successful set ups of the Italian industrial system.

Nevertheless often the plant engineering and management solutions adopted in these districts seem to be mere extracts of models created for individual companies, and not the result of a specifically dedicated approach.

A consequence of such an approach is the underestimation of the difficulties in which the single units of the district operate. The small size unavoidably implies for these firms a poor availability of resources to be invested in ambitious projects

\footnotetext{
* Corresponding author. Tel.: + 39-0432-558000; fax: + 39-0432-558027.
}

E-mail address: meneghetti@uniud.it (A. Meneghetti). 
concerning service activities external to their core business. Thus, in these fields, the classical paths of creation and transfer of the technological innovation are fruitless. On the other hand, the risk is to leave, unexploited, the great potentialities of the district firms. Being geographically concentrated and having to cope with similar problems, they could find in the common initiative the way, not only to overcome their own weak points, but also to create a virtuous circle of value generation. The common demand of services should be answered by creating structures internal to the districts, able to exploit the physical closeness to the potential customers, thus resulting in a competitive edge as compared to external suppliers. In this way, double advantage can be obtained of services at lower costs for the single firms and of a redistribution of the resulting richness within the district in terms of employment and investments in advanced technology.

In these terms, waste disposal appears to be a field where, maybe more than elsewhere, the enormous potentialities connected with a district approach instead of a mono-company one are evident. After the entry into force of Ronchi Decree (D.L. 22/1997), all Italian companies became responsible for the disposal of the generated waste, which can be sent to landfill only if inert or downstream recovery processes with costs are met. To be added are the territorial provisions aimed to avoid the "waste tourism" with the necessity, as a consequence, to find in the market structures as close as possible to the place of production of the waste.

An industrial district produces a large amount of waste through firms, which are individually too small not only to directly dispose of their own working residuals in plants with suitable performances, but also to exercise an important contractual power towards the external companies supplying this service. Yet the geographical concentration and the homogeneity of the waste produced make immediately manifest the advisability of creating proper plants on duty for the whole district and designed to make the most of the waste product types and quantities. In this way, clear advantages could be obtained for the waste transport, which would be performed within modest distances in compliance with ministerial directives, and for the capability of meeting the particular needs of the district through personalized and technologically updated plant solutions, sufficiently sized to reach the efficiency values imposed by law. All this would result, in the end, in a resource of competitive advantage for the whole district thanks to lower disposal costs compared to the competitors' ones and to a lower adverse environmental impact. This last aim, being almost completely delegated to a common structure, could be pursued by using suitable resources with the view of a continuous improvement, such as wished by the European directives.

The small companies of the district, characterized by a natural wariness of their own direct competitors, anyway often need an external catalyser agent in order to make the separately small resources meet in a common collector able to give effective answers for all district operators. In these terms, the University is a privileged subject as it is institutionally above the parties and having as a task, among others, the promotion of the scientific-technologic progress of the area in which it operates.

Later on, this report will illustrate the experience of the authors in designing a plant for the waste recovery in the district of Friuli Venezia Giulia; the plant is performing during its commissioning period and will be officially started-up 
at the beginning of 2002. It will be also shown how the methodological instruments typical of the academic world (simulations, proof campaigns, etc.) can be usefully directed towards the creation of innovative plant realities. The following paragraphs, therefore, will describe the case of the industrial district by highlighting the problems specifically related to the waste disposal (Section 2), then illustrating the plant solution found at district level (Section 3) and its economics (Section 4), and the possible future developments (Section 5).

\section{The peculiarities of the industrial district}

The industrial district is definitely a particular example of productive concentration. Located on a surface covering $210 \mathrm{~km}^{2}$ in the provinces of Udine and Gorizia are 1030 firms $^{1}$ specialized in the manufacture of chairs and tables and able to guarantee a job to over 10,000 employees. From an examination of these figures, it is immediately noticeable how extremely small the middle size of these firms is in terms of employees: the average number is 8 employees per firm and $65 \%$ of the firms do not exceed 9 people.

The most interesting aspect is the productive volume achievable by an industrial structure of this kind, constituted by small economic operators organized on the basis of the chair and wood-working supply chain. Within this limited territorial range about 60 millions chairs are produced every year, which corresponds to $80 \%$ of the Italian output and to $50 \%$ of the European one.

The localization of the productive processes in such a limited area leads to the presence of considerable quantities of production scraps which, the working processes being similar, are homogeneous and "typical". Table 1 summarizes the results of the waste typological analysis on the basis of the waste registration forms of the district companies. Three "macro-classes" are recognizable namely, woodworkingwaste products, varnishing residuals and packing.

The wood residuals generated in the district are, for the most part, internally recycled for the manufacturing of products such as root-like covering, panels etc. Another part is directly employed as an alternative fuel in the small company boilers used to satisfy the thermal needs of the single units. The remaining amount of wood material (about 12,000 tons/year) does not find any collocation, save for the transport to landfills.

As far as the varnishing and the packing waste are concerned, the usual procedure in the district was to send them to landfill at costs in the range of $0.18-0.21$ and 0.06-0.08 Euro/kg, respectively.

The chemical analysis allowed us to define the following average composition of the waste mix currently sent to landfills: $\mathrm{C}=48 \%, \mathrm{H}=5 \%, \mathrm{O}=35 \%, \mathrm{~S}=0.5 \%$, $\mathrm{I}=4 \%, \mathrm{~N}=0.5 \%$, and $\mathrm{U}_{\mathrm{m}}=7 \%$ (hygroscopic water). The lower heating power of these

\footnotetext{
1 Seventy percent of the companies are concentrated in a smaller area of $100 \mathrm{~km}^{2}$ only, the so called "chair triangle", in the surroundings of Manzano, San Giovanni al Natisone e Corno di Rasazzo, all in the province of Udine.
} 
Table 1

Typological analysis of the chair-manufacturing waste

\begin{tabular}{lll}
\hline Waste macro-classes & Type & Output (tons/year) \\
\hline Waste from woodworking divisions & Wood scraps and chips & Wood shavings and sawdust \\
(cutting, drilling, smoothing, & Scraps and chips from treated & \\
moulding, etc.) & or faced wood \\
& Panel scraps and chips & \\
& Laminate scraps and chips & \\
Waste from varnishing divisions & Dust from sandpapering of & \\
(painting carousels, machinery & varnished surfaces & 4000 \\
and equipment washing, & Catalyzed and not usable & \\
sandpapering of varnished surfaces) & varnish residuals \\
& Polyester and polyurethane varnish & \\
& crusts deposited on the varnishing plants & \\
& Vinyl bonding crust \\
Packing & Not recyclable papers and cartons \\
& Plastic materials \\
& Pallets and not recyclable containers
\end{tabular}

waste products goes between $18.54 \mathrm{MJ} / \mathrm{kg}$ (for dry biomass) and $12.22 \mathrm{MJ} / \mathrm{kg}$ (for $30 \%$ moisture content), with an average value of about $17.60 \mathrm{MJ} / \mathrm{kg}(4200 \mathrm{kcal} / \mathrm{kg})$. Such a high heating power for a scrap material makes it desirable to consider its energy recovery. Sending the waste to landfills turns out to be unfit due to the poor biodegradability of the product types involved.

Easy to understand, therefore, is the necessity for a technical and organizing solution able to solve the problem of the disposal of about 20,000 tons/year of waste and to reduce, at the same time, the economic and strategic dependence on disposal operators from outside the district.

The European guidelines, besides considering the thermo-utilization of the waste products as the main target after recycling, particularly stress the principles of proximity to the production centers and of self-sufficiency referring to the waste produced in one's own area. As a consequence, a waste-to-energy plant for the industrial waste of the district firms, to be placed inside the district itself, appears the most suitable solution for efficiently and successfully carrying out the waste disposal in full compliance with the regulations.

\section{Waste-to-energy solution for the industrial district}

The plant size has been chosen so that the industrial district could observe the principle of self-sufficiency in disposing of its waste products. The plant has been designed, therefore, for the disposal of 20,000 tons/year, under continuous operation 
conditions, with a gross utilization factor of 0.85 with respect to the solar year. The hourly potentiality varies between 2300 and $2700 \mathrm{~kg} / \mathrm{h}$ according to the different heating energy present in the 3-waste-type mix approved by the public bodies, namely varnishing crusts, packing materials and wood scraps. The plant has been studied to manage this entry-waste variability, which influences the mass flows passing through the plant, by means of inverters that control the flows of solid and gaseous substances. The aim is to obtain the machine minimum electric power consumption, performances being equal, and to limit the operation intermittence.

Once the waste treatment capacity had been defined, the most suitable plant solution had to be found. The analysis of the reported experiences, both at prototype and at commercial level (see for example [1-4]), showed that the solutions applicable to the case under examination could be brought back to the waste incineration through a grate combustion chamber or rotary kiln with energy recovery through a steam turbine, or to the waste gasification for feeding an internal combustion diesel engine [5]. The special waste mix under examination implies problems of dirtiness because it generates low-melting suspended ash; this excluded the solution based on the endothermic motor. Also in the most traditional configuration with combustion followed by a steam cycle, however, the steam generator will have to be equipped with a strong cleaning system for the tube bundles [6]. Concerning the choice of the furnace type, the solution with a moving grate has been preferred considering the medium size of the plant, which otherwise would have required a rotary kiln of remarkable dimensions (about $60 \mathrm{~m}^{3}$ ). Furthermore the interface between the static part and the rotating would to the problem of dust leakage in the surrounding area, which we wanted to avoid.

As regards the visual impact, which is of particular importance to increase the community's acceptation degree, since the industrial areas are close to the residential ones, the waste-to-energy plant has been landscaped with the district firms by adopting their external shape. The plant development, therefore, has been of an extensive type as the technical volumes had to be contained in 2 industrial sheds similar to the ones of the surrounding activities (even the storage silos merge with the ones of the surrounding companies). From an ergonomic point of view, the choice of the color for the supporting structure and machinery is peculiar. A particular study has been carried out upon this aspect with the aim to create at the same time a comfortable but highly-safe working environment also taking into consideration the better visibility and recognizability for operators of all the internal elements of the system.

The following sections, after an illustration of the choice criteria for the plant location (Section 3.1), will show the characteristic aspects of the various sections into which a waste-to-energy plant can be divided [6].

\subsection{Plant location}

The area inside the district for the location of the plant has been chosen on the basis of two main principles: minimize the distances from the potential customers and cause the minimum environmental impact on the territory. 
As regards the first aspect, a barycentric position with respect to the waste sources makes it possible to reduce both the waste transport costs and the vehicle traffic pollution in the district from which the material to be incinerated will be conveyed to the plant. It will also meet the requirement of proximity indicated by the community provisions. Once the possible areas on the municipal plans and of the presence of suitable characteristics for future manpower enlargements (Section 5) have been identified, the static moments method has been applied at first with the aim of reducing the number of alternatives.

As regards the second aspect, the analysis focused on the air quality achievable by placing the plant in the two best alternatives, selected according to the previous mentioned criteria. Since the plant is built inside and for the district, this latter represents on the one hand the promoter of the introduced environmental alterations, if any, and on the other hand the receiver of the same. The high density of companies and civil houses often hide one another, others, as a consequence of irrationalized building development carried out in the past. The plant, therefore, is asked to manage the environmental problem of the waste by granting to the local community the maximum protection of its own environmental resources. In this regard, a careful analysis of the ground-level concentrations has been carried out by simulating through the industrial source complex (ISC) model the plant operation with the highest emission values allowed by the norm and by positioning it in each of the two selected alternatives. The resulting air quality has been evaluated through the air quality guarantee index $G_{i}^{k}$, for each $i$ th pollutant and $k$ th zone into which the analyzed territory has been sub-divided, and defined as follows:

$$
G_{k}^{i}=\left[1-S_{k}\right]-\frac{F_{k}^{i}}{\left(C_{l}\right)^{i}}-\frac{I_{k}^{i}}{\left(C_{l}\right)^{i}}
$$

where: $F_{k}^{i}$ is the background concentration of the $i$ th pollutant attributable to the zone $k ; I_{k}^{i}$ the concentration in the $k$ th zone of the $i$ th pollutant attributable to the plant;

and $\left(C_{l}\right)^{i}$ the standard value (max. concentration provided for by law) for the $i$ th pollutant;

$S_{k}$ the safety margin compared with the law limits attributed to each $k$ area of the territory, is calculated starting from a basic safety factor $s$, which is homogeneous for the entire analyzed area and indicative of the higher protection degree requested by the local community compared with the national limits, and from a factor $z_{k}$, which is bound to the characteristics of $k$ th zone, according to the equation: $S_{k}=s\left(1+z_{k}\right)$.

In particular, the safety margin allows the introduction of the evaluation of the peculiarities of the various district areas in terms of different air-quality requirements: consider, for example, a playing field compared with an industrial complex. The $z_{k}$ factors [7] have been chosen by fixing a minimum value according to the usedesignation class (residential, industrial, agricultural or green) of each area, and by further differentiating a single class on the basis of various factors such as: the worker density: the perimeter shared with built-up zones for the industrial areas; the demographic density for the residential ones; the presence of denomination of 
origin controlled (DOC) vineyards for the agricultural ones and of natural reserves for the green ones.

The potential location areas, therefore, have been assigned an aggregate value of the air-quality index in order to find out the most valid alternative from an environmental point-of-view.

\subsection{Stocking, preparation and feeding areas}

The function of the stocking system is to separate the operations of scrap collection from the district firms and its proper preparation from the feeding of the continuously working combustion chamber. Besides, it ensures a minimum safety stock in case of non-waste collection.

The preparation system has to guarantee as even a waste mixture as possible in order to dampen the variations of heating power in the combustion chamber and of the flue-gas composition, with particular reference to pollutants. It also has to provide material of such a size that the times required to complete combustion do not exceed the maximum residence time expected inside the furnace. Usually the preparation of the material to be sent to the incinerators is continuously carried out with the constant presence of the operator in charge; in this case, instead, an innovative choice has been taken by de-coupling, with respect to time, the daily grinding-phases from the combustion chamber continuous feeding. On one hand, this solution reduces the personnel demand and permits one to release the operators from uncomfortable and repetitive jobs. It permits, as well, the elimination of the noise resulting from the night grinding, thus avoiding any possible objections from the resident population, whose houses are quite near the industrial area. Yet, on the other hand, it presents realization and management difficulties linked above all to the material nature which is partly filamentous, adhesive and tending to agglomerate. For this reason the handling and stocking systems have been designed with the aim to avoid as far as possible the use of screws, keeping them solely where a material dosing is necessary, and preferring instead plate conveyors and silos with extraction combs.

The system has been designed to reach a high degree of flexibility, which is necessary to manage the product variations of the waste conveyed. Referring to the scheme of Fig. 1, the mixing of three material typologies is realized through the operator manual charging; the operator can chose what to put into the two grinders and the 2 silos, where a differentiated stocking can be realized with the aim of selecting a waste with a higher or lower (LHV) lower heating value content, so that i.e. transients can be properly managed.

Once fixed, the transport capacity necessary to ensure the right feeding of the combustion chamber, some simulations of the adding system have been carried out in order to chose the most suitable speed. The increase of the conveyor operating speed implies a reduction of the purchase price, especially of the belts with reduced widths, but also a reduction of the reliability of the same. By interviewing the suppliers, it was possible to assume a relationship between transport speed value and reliability of the various components, as well as to establish the maintenance capabilities of the machinery in the event of failure. A simulative 


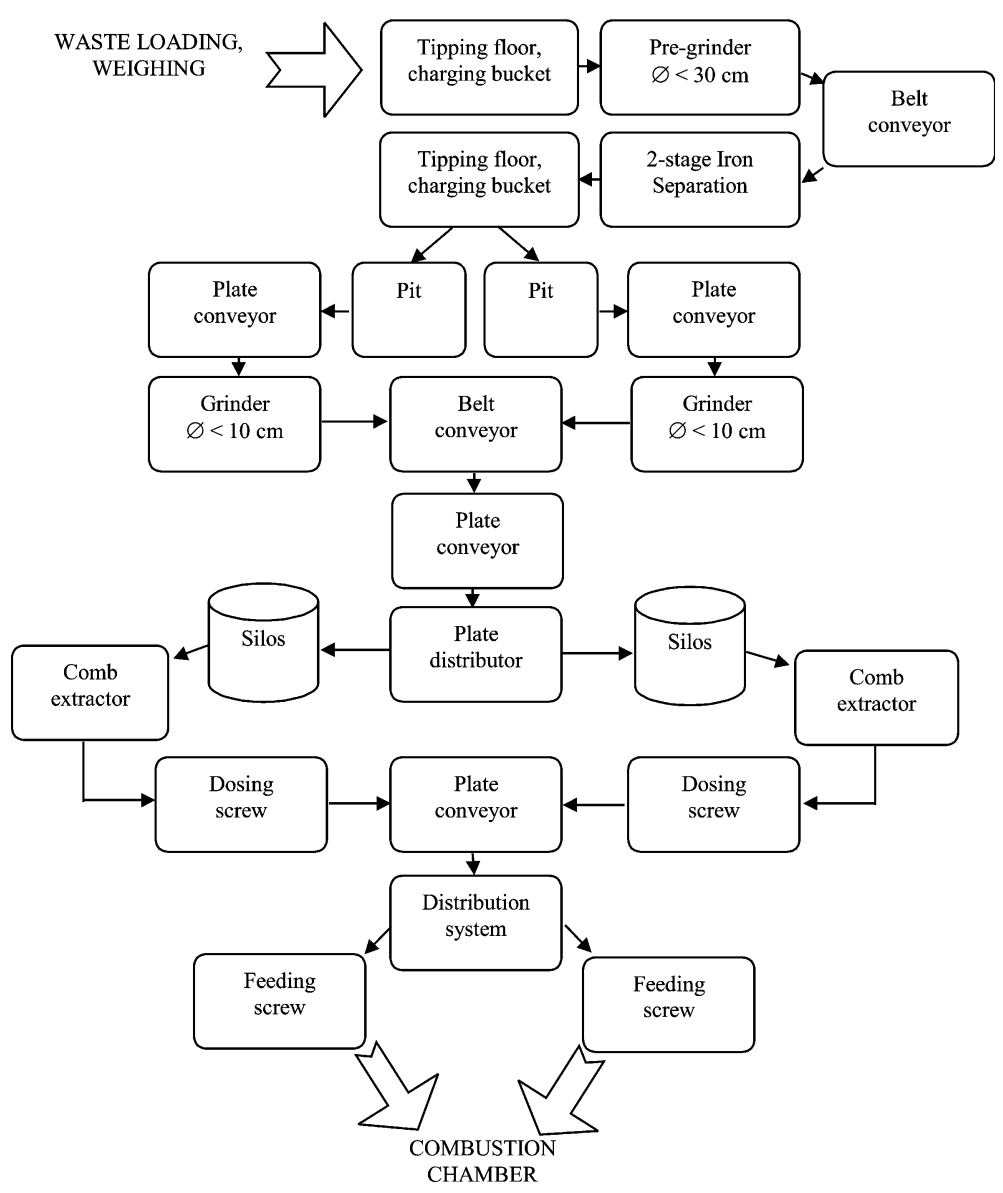

Fig. 1. Stocking, preparing and feeding system.

experiment has proved how the employment of quick transporters exposes the plant, in the medium-time period, to the risk of considerable losses for non-output due to faults of the feed system (i.e. a speed increase of $50 \%$ causes a non-output of $11.2 \%$, while by doubling the reference speed the not-output will be $61.6 \%$ ). The choice thus is directed towards the slower configurations.

The entire stocking station downstream of the grinders is kept under vacuum in order to avoid dust and smell leakages. A stripping system with external air is provided as well for possible solvent vapors, which could develop during the phases of grinding and stocking into silos. Thanks to this solution, the input of polluting or smelly substances into the surrounding environment can be avoided and the formation of explosive mixtures prevented. The sucked volumes are mixed with the combustion air and then conveyed into the combustion chamber, where they undergo a complete oxidation process. 


\subsection{Combustion equipment}

Given the uniqueness of the waste mix to be treated and, therefore, the poor availability of reference experiences, it has been preferred to use a traditional combustion plant of great reliability such as the grate furnace. The rotating furnace combustion chamber, often used for high LHV waste of industrial origin, can experience tightness between the rotating element and the fixed part of the system, with the consequent danger of harmful gases and dust inputs into the work place, especially during the operation transients.

The thermochemical transformation section consists of a combustion chamber (CC), with primary-air input from under the grate and secondary air input through nozzles located on the waste entry side walls and front wall, followed by a postcombustion chamber (PCC). In order to reduce the combustion bed width, thus allowing the lateral input air to better homogenize the process, the $\mathrm{CC}$ volume (68 $\left.\mathrm{m}^{3}\right)$, as well as the PCC one $\left(80 \mathrm{~m}^{3}\right)$, are obtained with 2 parallel chambers. Fig. 2 shows the section model made with software for a three-dimensional fluid dynamic simulation (Fluent).

The post-combustion chamber has been realized in compliance with the commitment of a residence time not shorter than $2 \mathrm{~s}$ imposed by the President of the Republic's Decree 915/82 in force in the first phase of the project, which also fixed a crossing speed of $10 \mathrm{~m} / \mathrm{s}$ between CC and PCC. The post-combustion chamber construction obligation, including the above-mentioned features, has declined with the entry into force of the subsequent Ronchi Decree 22/1997, which allows positioning of the recovery boiler straight upon the furnace. Yet, whereas this system on the one hand allows the increase of the energy yield thanks to the irradiation benefits, on the other hand it makes the actual exhaustion of the combustion

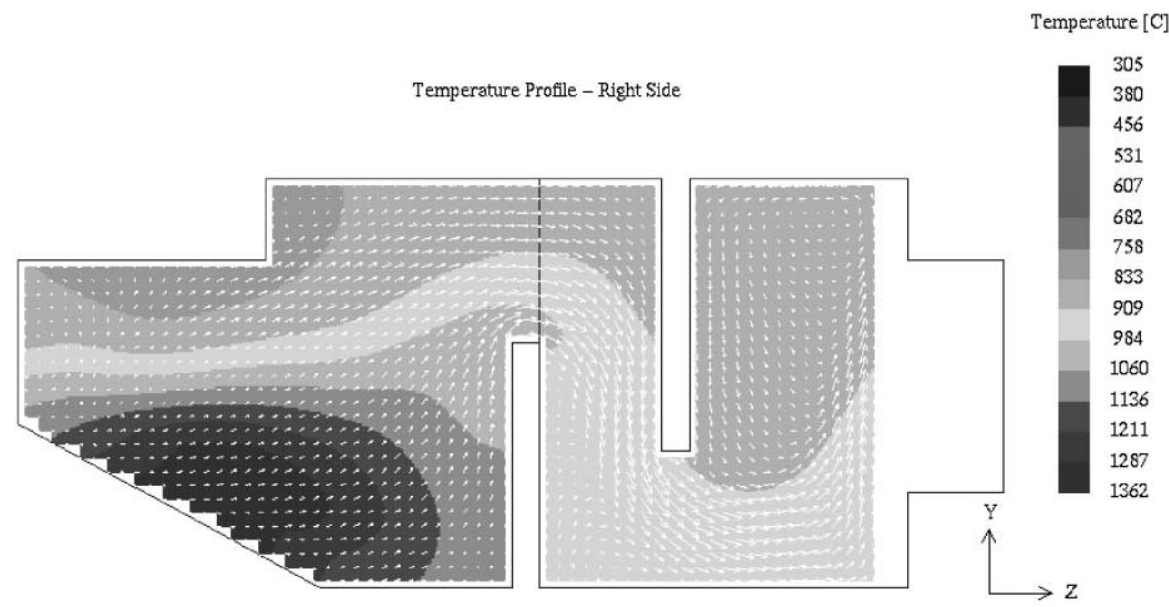

Fig. 2. Temperature profile in combustion and post-combustion chambers. 
process more difficult if compared with having a post-combustion chamber. Due to the fragility of the material, whose thermo-destruction remains the principal target of the plant, it has been chosen to maintain the original combustion process exhaustion system.

Since wood dust is also produced as working scrap ( $\mathrm{LHV}=4000 \mathrm{kcal} / \mathrm{kg}$ ), its disposal has been met by blowing it into the furnace such as to intercept in the CC final part the hot gases generated by the grate, with the aim of sustaining the combustion process. Extremely improbable, as a result of this, is the operation of the methane post-combustion burners, which according to law should intervene each time when the temperature of the thermo-destruction section descends below $850{ }^{\circ} \mathrm{C}$. Thus the peculiar features of the waste produced can be used to increase the efficiency of the thermo-destruction system and to reduce, at the same time, the supply of traditional fuel, increasing, therefore, the corresponding raw material factor of the plant [6]. In order to reduce the $\mathrm{NO}_{x}$ emissions by directly acting on their forming mechanisms [8], the flue-gas recirculation possibility has been considered, that is to say, to reduce the oxygen content in the combustion air by mixing a fraction of the produced flue-gases with the external air in a designated underground space in front of the combustion chamber. The experiences reported in literature about the optimal recirculation percentages implemented in real plants show extremely different values (see for example [9]) so suggesting a strong dependence on the waste typology and on the combustion chamber morphology. It has been decided, therefore, to start an experimental campaign in the waste-to-energy plant provisory operation period. The intention is to relate the flue-gas recirculation technique with the actually achievable environment performance, thus going beyond the limits of the existing computational fluid-dynamic software. With the aim of opposing the thermal $\mathrm{NO}_{x}$ formation mechanisms, the experimental campaign will be extended to the thorough analysis of the differential use of the secondary-air input nozzles. This differential use should give a higher control capacity of the combustion chamber's internal temperatures, as highlighted by some theoretical studies [10].

\subsection{The energy recovery section (see Fig. 3)}

The water extracted by the de-aerator at a temperature of $110{ }^{\circ} \mathrm{C}$, with a flowrate of $14.50 \mathrm{t} / \mathrm{h}$ at maximum steady state, is brought to $215^{\circ} \mathrm{C}$ in the economizer and sent to the 2 lower drums of the steam generator. The upper drum is reached both directly for natural convection through the water tubes of the evaporator and after feeding the water jackets in the furnace wall. The saturated steam is then brought to $410{ }^{\circ} \mathrm{C}$ in the superheater and sent into the turbine. The system is provided with a turbine bypass in order to close the cycle in the condenser in case of the absence of electric energy demand.

The features of the steam generator, which is a natural circulation vertical water tube type with 3 drums, are summarized in Table 2. The typical dimensions of the 2-stage action turbine with the possibility of intermediate bleeding are shown in Table 3 . 


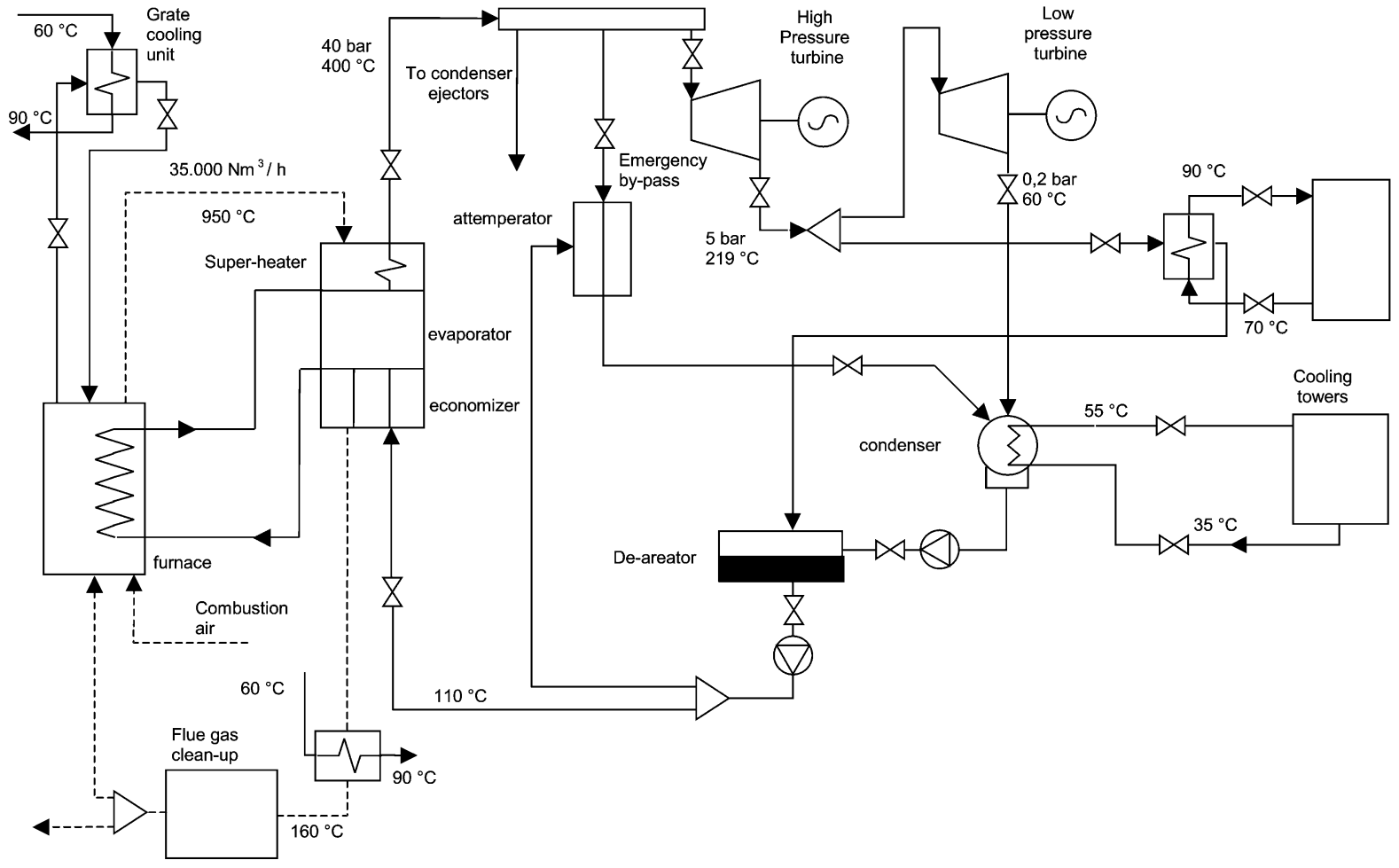

Fig. 3. The energy-recovery section of the waste-to-energy plant. 
Table 2

Steam-generator features

\begin{tabular}{lc}
\hline Generator features & Values \\
\hline Steam flowrate & $14 \mathrm{t} / \mathrm{h}$ \\
Working pressure & $40 \mathrm{bar}$ \\
Super-heating temperature & $410^{\circ} \mathrm{C}$ \\
Feeding temperature & $110^{\circ} \mathrm{C}$ \\
Super-heating exchange surface & $190 \mathrm{~m}^{2}$ \\
Evaporation exchange surface & $650 \mathrm{~m}^{2}$ \\
Economizer exchange surface & $535 \mathrm{~m}^{2}$
\end{tabular}

Table 3

Steam-turbine features

\begin{tabular}{ll}
\hline Turbine features & Values \\
\hline Steam's maximum flowrate & $15.1 \mathrm{t} / \mathrm{h}$ \\
Steam nominal flowrate & $14.5 \mathrm{t} / \mathrm{h}$ \\
Inlet steam pressure & $40 \mathrm{bar}$ \\
Inlet steam temperature & $400^{\circ} \mathrm{C}$ \\
Bleeding pressure & $5 \mathrm{bar}$ \\
Outlet pressure & $0.2 \mathrm{bar}$ \\
Rotation speed & $1500 \mathrm{rev} / \mathrm{min}$ \\
Nominal power & $2560 \mathrm{~kW}$ \\
Electric energy exit voltage & $6300 \mathrm{~V}$
\end{tabular}

As regards the flue gas coming out from the economizer unit at $220^{\circ} \mathrm{C}$, it passes through a pipe-bundle exchanger-dissipator, to be brought back then to such a temperature $\left(180{ }^{\circ} \mathrm{C}\right)$ as not to damage the bag filter of the downstream cleaningsection.

Though being planned for the production both of electricity and thermal energy, the current system configuration will only convert the waste heating power into valuable energy to be supplied to the electric net. This is because, for the first 8 years of operation, the plant can count on the facilitated regime of the Interdepartmental Committee on Prices 6/92, which promotes the production of electric energy by paying it $0.17 \mathrm{Euro} / \mathrm{kWh}$, when the firms usually pay an average of $0.10 \mathrm{Euro} / \mathrm{kWh}$ for their electrical inputs. By producing electric energy only, an avoided $\mathrm{CO}_{2}$ emission of about 9000 tons/year can be achieved, due to the ceased supply of electric energy to the district by a remote electric generator. It is useful to point out that the $\mathrm{CO}_{2}$ produced by the plant, on the contrary, can be associated not to traditional fuel, but to renewable resources; the plant takes shape consistent with the carbondioxide world production limitation plan aimed at facing the problem of the greenhouse effect. This plan, as required by the Kyoto agreement (1997), is now concretely encouraged in the regional development programs of Friuli Venezia Giulia. 


\subsection{Flue-gas clean-up}

The flue gas cleaning section represents an important subset of a waste-to-energy plant both for the technical and the financial resources required for its realization. The most common configurations today consider the installation of a cyclonic or multicyclonic separator for the precipitation of the big-grained particles and of a successive bag filter or electrofilter able to guarantee final dust concentrations within the limits imposed [11]. The elimination of acid compounds is achieved by injecting, along the flue-gas cleaning line, substances such as lime or sodium bicarbonate [12], often inside reaction towers. The combination of this equipment causes very high head losses and a certain difficulty of integrated management. Therefore, the cyclone/multicyclone and the reaction tower usually present in a cleaning section have been replaced with a unique device able to fulfil two requirements. The first one is to separate the big-grained particles present in the flue gas, including the incandescent particles, if any, which could damage the bag filter placed downstream of the flue-gas treatment line. The second one is to eliminate the acid compounds present in the combustion products (e.g. the inlet $\mathrm{HCl}$ concentration can reach $600 \mathrm{mg} / \mathrm{Nm}^{3}$ ) thus creating a volume where flue gas and sodium bicarbonate can suitably mix.

The new structure puts together a cyclonic pre-separator with a reaction tower and, for this reason, has been called the Cytow (Cyclon + tower); the device has been patented [13].

The new plant configuration has been studied on the basis of the above mentioned requirements and with respect to the following targets: reduction of the load losses as compared with the traditional concatenation of cyclone/multicyclone-reaction tower, optimization of the surface occupation thanks to a vertical development of the equipment, reduction of the transport channels with consequent load loss limitation and material savings, absence of moving parts influencing the system reliability and the corresponding maintenance costs.

The structure optimization has been based on three-dimensional fluid dynamic simulations, carried out through a solver of the Navier-Stokes equations, fit for complex geometries (Star-CD) and applying the $k-\epsilon$ model for the turbulence handling [14]. Attention has been especially paid to the analysis of the fluid dynamic field related to different sections of the tower, of the semicyclone separation efficiency and of the trajectory of the sodium bicarbonate particles [15].

The configuration reached (see Fig. 4) includes a semicyclone, an ascendent reaction tower and a descendent reaction tower. In the semicyclone, the partial separation of the particles is achieved thanks to the inertial forces acting on the particles; the semicyclone includes a tangential inlet channel, which guarantees the flue-gas passage inside the semicyclone with limited head losses, and the body of the semicyclonic separator which conveys the flue gas through a circular path of $270^{\circ}$ towards the ascendent central tower. This latter consists of a conic-shaped collecting and discharging device, where the particles are collected after separation in the semicyclone; a Venturi pipe, whose section narrowing is exploited for the injection of sodium bicarbonate; a part of channel with constant section; and the connection 

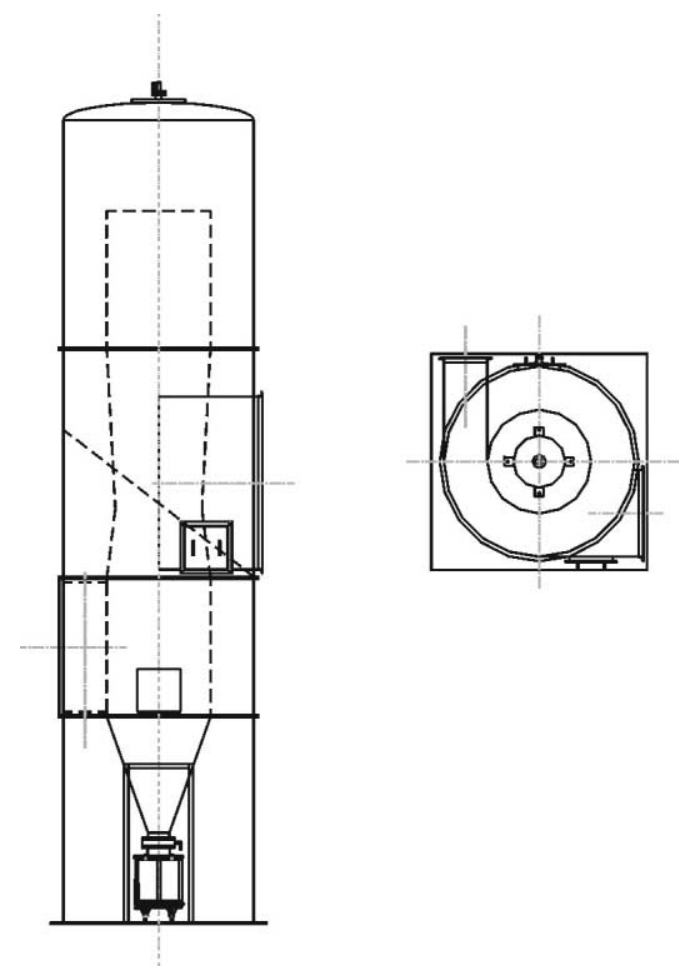

Fig. 4. Prospect of the Cytow reaction tower.

with the descendent tower. In order to successfully manage the flue-gas flow-rate variations consequent to the variability of the processed waste (Section 3), a bi-taper pin has been introduced, which by moving along its vertical axis is able to reduce or increase the Venturi throat passage section. In this way, the speed is optimized in order to limit the load losses: too low values cause a precipitation of the bicarbonate and too high levels impede a sufficient contact time with the flue gas. The descendent reaction tower consists of a constant section channel and an exit, tangentially positioned at $90^{\circ}$ with respect to the entry, in order to exploit the circular component of the speed given to the flue gas by the semicyclone. Its aim is to guarantee a sufficient mixing time between flue gas and bicarbonate thanks to the wide passage section.

We stress the fact that the plant is equipped with an injector of active carbon to be mixed with the bicarbonate, now inoperative since the emissions (see Table 4) are below the legal limits.

The installation of the Cytow permits, compared to the traditional solution, the reduction of load losses by about $1000 \mathrm{~Pa}$, which at the steady flowrates is equivalent to $25 \mathrm{~kW}$ of electric power savings for the extractor fan. The resulting saving can be, therefore, estimated to be about 31,000 Euro/year, against an investment equal to about 77500 Euro. 
Table 4

Emission limits and actually registered values

\begin{tabular}{|c|c|c|c|c|c|c|c|}
\hline \multirow[t]{3}{*}{ Gaseous effluent } & \multicolumn{2}{|c|}{$\begin{array}{l}\text { Decree of the Ministry } \\
\text { of Industry }\end{array}$} & \multirow{2}{*}{\multicolumn{4}{|c|}{$\begin{array}{l}\text { Decree of the } \\
\text { Ministry of Industry } \\
\text { Limits }\left(\mathrm{mg} / \mathrm{Nm}^{3}\right)\end{array}$}} & \multirow[t]{3}{*}{$\begin{array}{l}\text { Measures } \\
\text { taken at stack }\end{array}$} \\
\hline & \multirow{2}{*}{$\begin{array}{l}\text { Periodical } \\
\text { measures } \\
\text { every six months }\end{array}$} & \multirow{2}{*}{$\begin{array}{l}\text { Continuous } \\
\text { measures }\end{array}$} & & & & & \\
\hline & & & A & $\mathrm{B}$ & $\mathrm{C}$ & $\mathrm{D}$ & \\
\hline Carbon monoxide (CO) & & $\mathrm{X}$ & 50 & 100 & & & $20-40$ \\
\hline Particulate matter & & $\mathrm{X}$ & 10 & 30 & & & $1-5$ \\
\hline $\begin{array}{l}\text { Organic substances } \\
\text { expressed in total organic carbon }\end{array}$ & & $\mathrm{X}$ & 10 & 20 & & & $3-7$ \\
\hline $\begin{array}{l}\text { Chlorine inorganic } \\
\text { compounds } \\
\text { expressed as } \\
\text { hydrochloric acid }(\mathrm{HCl})\end{array}$ & & $\mathrm{X}$ & 10 & 40 & & & $1-5$ \\
\hline $\begin{array}{l}\text { Fluoride inorganic compounds } \\
\text { expressed as } \\
\text { hydrofluoric acid (HF) }\end{array}$ & & $\mathrm{X}$ & $1^{(*)}$ & $4^{(*)}$ & & & 0,2 \\
\hline $\begin{array}{l}\text { Sulfur oxides expressed as } \\
\text { sulfur dioxide }\left(\mathrm{SO}_{2}\right)\end{array}$ & & $\mathrm{X}$ & 100 & 200 & & & $20-40$ \\
\hline $\begin{array}{l}\text { Nitrogen oxides expressed } \\
\text { as nitrogen dioxide }\left(\mathrm{NO}_{2}\right)\end{array}$ & & $\mathrm{X}$ & 200 & 400 & & & $100-150$ \\
\hline Cadmium $(\mathrm{Cd})$ and thallium $(\mathrm{Tl})$ & $\mathrm{X}$ & & & & 0.05 & & 0.02 \\
\hline $\begin{array}{l}\text { Mercury and its compounds } \\
\text { as mercury }(\mathrm{Hg})\end{array}$ & $\mathrm{X}$ & & & & 0.05 & & $<0.02$ \\
\hline $\begin{array}{l}\text { Antimony }(\mathrm{Sb}), \text { arsenic }(\mathrm{As}), \\
\text { lead }(\mathrm{Pb}), \text { chrome }(\mathrm{Cr}), \\
\text { cobalt }(\mathrm{Co}), \text { copper }(\mathrm{Cu}), \\
\text { manganese }(\mathrm{Mn}), \text { nickel }(\mathrm{Ni}), \\
\text { vanadium }(\mathrm{V}), \text { tin }(\mathrm{Sn})\end{array}$ & $\mathrm{X}$ & & & & 0.5 & & 0.167 \\
\hline $\begin{array}{l}\text { Polychlorinated } \\
\text { dibenzo-para-dioxins } \\
\text { and polychlorinated } \\
\text { dibenzofurans } \\
\text { (PCDD, PCDF) }\end{array}$ & $X$ & & & & & $0.1 \times 10^{-6}$ & $<0.02 \times 10^{-6}$ \\
\hline $\begin{array}{l}\text { Polycyclic aromatic } \\
\text { hydrocarbons }\end{array}$ & $\mathrm{X}$ & & & & & 0.01 & $<0.002$ \\
\hline
\end{tabular}

a A: daily average value; B: hourly average value; $\mathrm{C}$ : average value detected for a sampling period of 1 $\mathrm{h}, \mathrm{D}$ : average value detected for a sampling period of $8 \mathrm{~h} ;\left(^{*}\right)$ hydrofluoric acid + hydrobromic acid $(\mathrm{HF}+\mathrm{HBr})$.

As far as the $\mathrm{NO}_{x}$ is concerned, a production of $350-400 \mathrm{mg} / \mathrm{Nm}^{3}$ at $11 \%$ of $\mathrm{O}_{2}$ is calculated. These values have been detected without using the flue-gas recirculation, which is at present under experimentation. For their abatement, a selective noncatalytic $\mathrm{NO}_{x}$ reduction (SNCR) system has been installed with the injection of urea $(40 \mathrm{~kg} / \mathrm{h})$ into the post-combustion chamber.

Table 4 indicates the emission limits according to Italian regulations, which the plant has to respect, and the obligatory measurements at the stack. As can be 
deduced from the recorded data, particularly low values of pollutants are reached in connection with the simplified plant engineering, which means with the lowest number of components possible. This confirms our conviction that the complexity of the solutions often mentioned in the technical literature is sometimes not only useless but also self-defeating in terms of energetic consumptions and the system's reliability (which obviously decreases with the increase of the units in series).

\subsection{Plant's solid-mass flow}

Incineration and flue-gas treatment facilities imply the formation of solid waste in different points of the plant, which have been characterised from the chemical-physical point of view through a sample analysis based on the following sample-taking points:

- deposit tank for combustion and post-combustion chamber ashes

- collect hoppers for the ashes deposited on the steam generator bottom

- ash container on the bottom of the reaction tower Cytow; and

- collecting bag for the bag filter ash

The sample specific weights defined together with the data on the produced ash volumes relative to 10 days of plant continuous operation, which have been drawn from the emptying or removing operations of the above mentioned collecting systems, allowed us to give the mass balance shown in Fig. 5.

\subsection{Electrical-energy inputs}

Electrical powers installed and average inputs are shown in Fig. 6.

As can be noticed, the most considerable figure is the one of the waste preparing and stocking section, so that we are evaluating the possibility of reducing it by transferring the grinding operations (the amount of which in terms of input power is about one third) to the collecting stations of the industrial scrap. While the energy produced by the waste-to-energy plant itself, and presently consumed in the plant, has a network supply value of 0.17 Euro/ $\mathrm{kWh}$, thanks to the incentives established by the Government, the energy purchased from the network by the stations would occur at 0.10 Euro/kWh, with an evident saving.

\section{Waste-to-energy economics}

The plant has been built as a solution to the problem of the disposing of the waste produced in the industrial district. Thanks to the waste-to-energy conversion with the sale of the electrical energy to the national network at a boosted price, the service can be offered to the firms of the district at a lower price than the one usually applied by the sector operators, yet maintaining a good profitability, which is a basic requirement considering the private character of the project. 


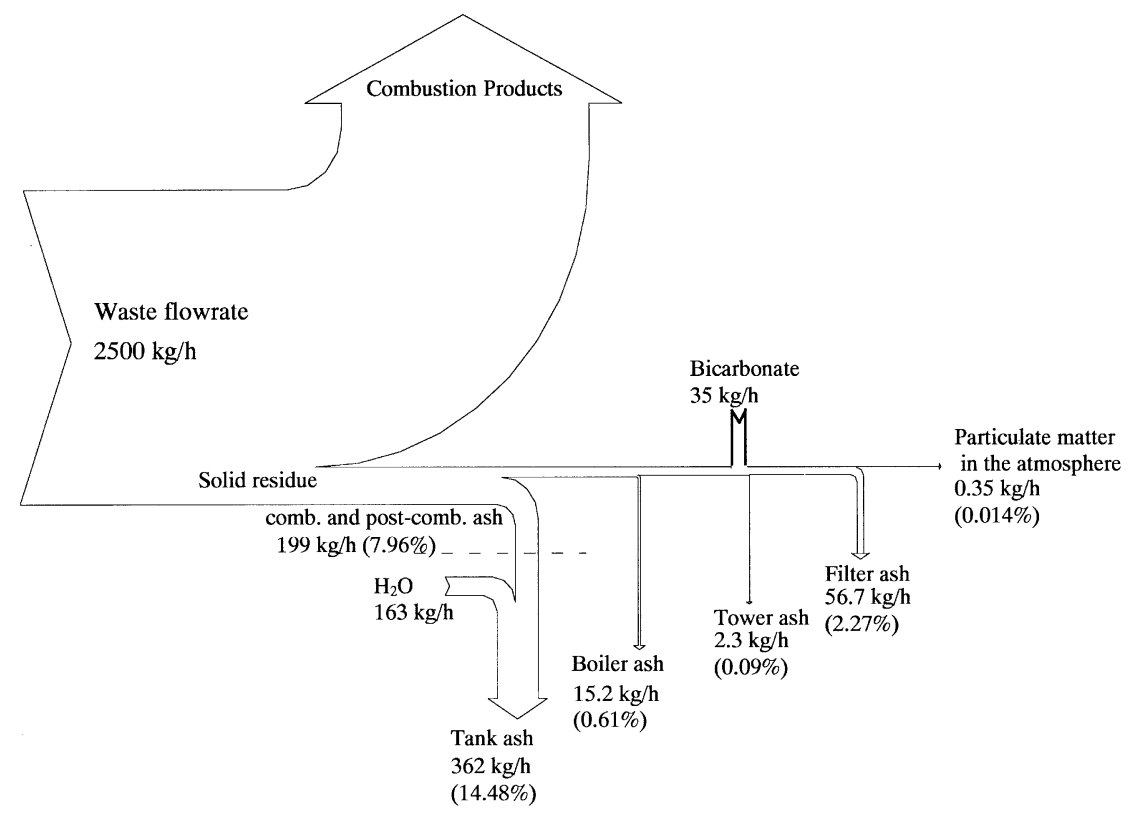

Fig. 5. Plant's solid-mass flow for a standard waste mix.

Table 5 shows the investment, which was necessary for the plant realisation, while Table 6 describes the present operation costs of the waste-to-energy plant.

As you can see from Fig. 7, the most relevant cost figures concern the final disposal in landfill of the solid residue of the plant and the preparation of the waste before entering the combustion chamber, which at present is carried out by an external firm, which operates the machinery of the plant's stocking and preparation section. The optimisation of the combustion process, now under study and experimentation, together with the reduction of the quantity of water necessary to cool the ash of the combustion and post-combustion chambers, which increases its weight, should help in achieving a remarkable reduction of the costs incurred for sending the solid residue to landfill. The possibility of grinding the waste in the collecting stations, at lower energy costs should bring a greater compensation of this outcome figure thanks to the increase of deliverable net power.

Regarding the positive cash flows, at present a net electrical power equal to 1400 $\mathrm{kW}$ can be assured to the national grid, which is deliverable for $612 \mathrm{~h} / \mathrm{month}$ at 0.17 Euro/kWh for the first 8 years of operation for a total of 147,795 Euro/month. The delivery price is destined to decrease to 0.034 Euro $/ \mathrm{kWh}$ after the boosted period established by the government.

The income derived from the waste disposal depends on the typology of the mix put into the combustion chamber. 


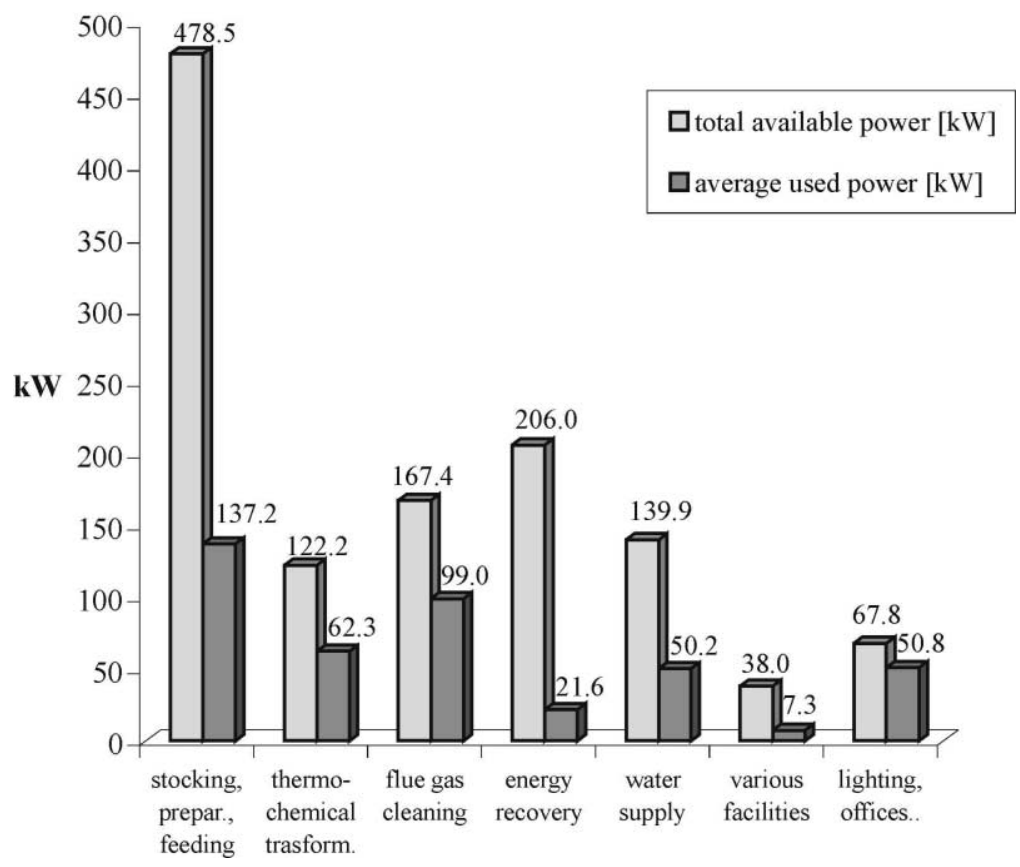

Fig. 6. Available power and average used power in the various plant sections.

As can be seen from Table 7, the three waste typologies permitted for the energy recovery from waste in the plant have different market values and different LHVs. Thus, the thermal charge in combustion chamber remaining unchanged, there are different treatable waste quantities. Three possible mixes have been identified (standard, reduced and intensive) with achievable cash flows as described in Table 7.

The simple payback-period of the investment is about 5 years (see Table 8), which is lower than the energy sale period at the boosted price. At the end of the eighth operation year, the plant capability to generate profit will be strongly reduced, thus making evident the need to improve the energy recovery of the plant through new plant engineering realisations as per the following (Section 5).

\section{Towards an integrated energy system}

The waste-to-energy plant has been planned, already from its conceptual and strategic formulations, for the maximum energy employment in terms of principle efficiency, by identifying from the beginning the further energy-environmental implementations bound to the district specific requirements and characteristics. The project as a whole consists of successive stages, which contribute to define a district integrated system, unique of its kind [16]. Its formulating principle is based on the constant consideration of three main aspects: industrial district needs, best available technologies and district technological and scientific advancement. 
Table 5

Investments made for the realisation of the waste-to-energy plant

\begin{tabular}{|c|c|c|}
\hline Item & Description & $\begin{array}{l}\text { Investment cost } \\
\text { (Euro) }\end{array}$ \\
\hline Civil works & $\begin{array}{l}\text { Sheds } \\
\text { Paving } \\
\text { Grouting works } \\
\text { Technical spaces } \\
\text { Trenches }\end{array}$ & $1,032,900$ \\
\hline Preparation section & $\begin{array}{l}\text { Grinding system } \\
\text { Stocking and feeding system }\end{array}$ & $\begin{array}{l}516,500 \\
774,700\end{array}$ \\
\hline $\begin{array}{l}\text { Thermochemical } \\
\text { transformation section }\end{array}$ & Combustion and post-combustion chambers & $1,549,400$ \\
\hline Energy-recovery section & $\begin{array}{l}\text { Boiler } \\
\text { Steam cycle } \\
\text { Turbine } \\
\text { Evaporation towers } \\
\text { Demineralisator } \\
\text { Electrical system } \\
\text { Automation and control } \\
\text { Hydraulic system } \\
\text { Green area } \\
\text { Offices (furniture,...) }\end{array}$ & $\begin{array}{l}1,032,900 \\
516,500 \\
619,700 \\
103,300 \\
129,100 \\
516,500 \\
258,200 \\
258,200 \\
51,600 \\
103,300\end{array}$ \\
\hline Cleaning section & $\begin{array}{l}\text { SNCR system } \\
\text { Cytow, bag filter } \\
\text { Tools (instrumentation, ...) }\end{array}$ & $\begin{array}{l}206,600 \\
516,500 \\
77,500\end{array}$ \\
\hline Total investment cost & & $8,263,400$ \\
\hline
\end{tabular}

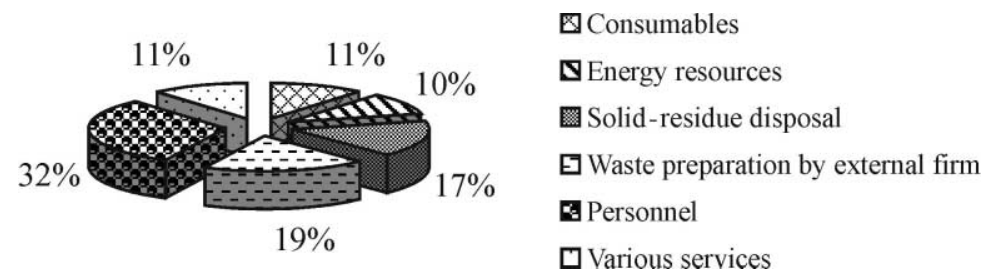

Fig. 7. Operation costs distribution.

With its current configuration, producing electric energy only, the waste to energy plant has a principle I yield of $16 \%$, considering the low efficiency of the small-sized steam turbines. Yet, potential energy resources are present, and not exploited, that could considerably raise the system's global efficiency, offering at the same time a service to the whole district. To be noticed in particular are:

- The possibility of intermediate bleeding between the high and low pressure bodies of the steam turbine at $219^{\circ} \mathrm{C}$ for thermal use. This solution can be used to 
Table 6

Operation costs of the waste-to-energy plant

\begin{tabular}{llrrr}
\hline Outcome description & $\begin{array}{l}\text { Measure } \\
\text { unit }\end{array}$ & $\begin{array}{l}\text { Monthly } \\
\text { quantity }\end{array}$ & $\begin{array}{c}\text { Unit cost } \\
\text { (Euro/unit) }\end{array}$ & $\begin{array}{r}\text { Monthly total } \\
\text { amount (Euro) }\end{array}$ \\
\hline Salt* & $\mathrm{kg}$ & 12,000 & 0.10 & 1178 \\
Urea & $\mathrm{kg}$ & 30,000 & 0.15 & 4648 \\
Normal bicarbonate & $\mathrm{kg}$ & 50,000 & 0.20 & 4204 \\
Boiler water additives & Intervention & 1 & 1807.60 & 1808 \\
Bottom ashes & $\mathrm{kg}$ & 350,000 & 0.05 & 10,795 \\
Bottom ashes transport & Transport & 12 & 154.94 & 1549 \\
Fly ashes & $\mathrm{kg}$ & 35,000 & 0.14 & 4839 \\
Fly ashes transport & Transport & 2 & 335.70 & 671 \\
Diesel fuel & 1 & 800 & 0.66 & 529 \\
Methane & $\mathrm{m}$ & 25,000 & 0.28 & 7101 \\
Waste preparation & & & 20,658 \\
Personnel costs & & & 33,570 \\
Tools, maintenance & & & & 10,329 \\
Electrical Energy & & & 3099 \\
Water & & & 181 \\
Services, cleaning & & & 1033 \\
Chemical analysis & & & \\
Total & & & & 930 \\
\hline
\end{tabular}

* Salt used in water demineralising for the steam generator and in water softening for the cooling towers.

Table 7

Material and cash flows depending on the adopted waste mix

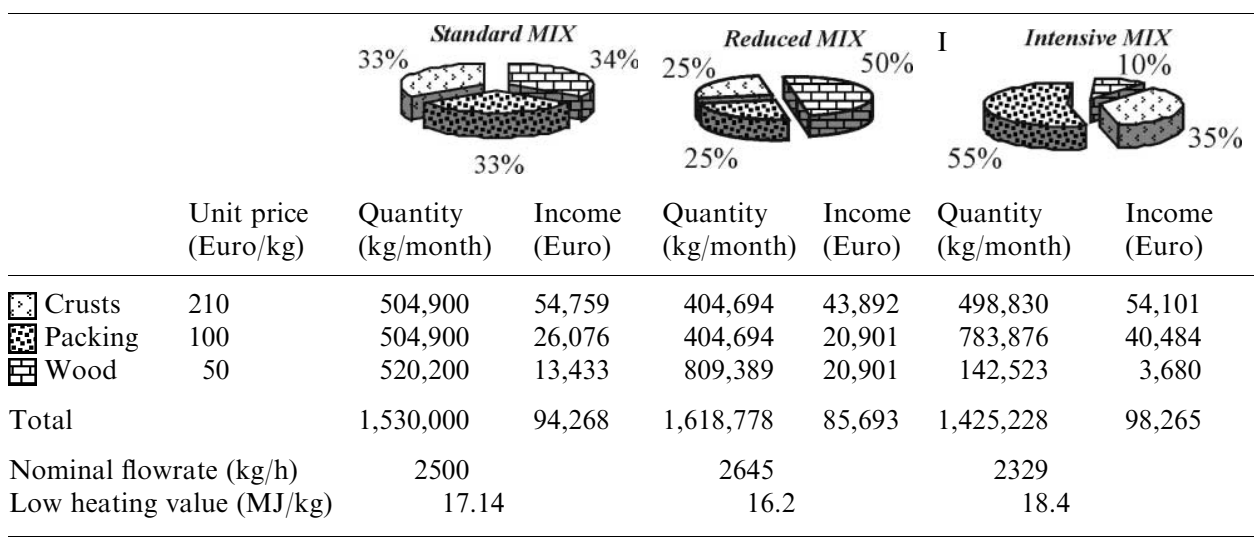

feed a district-heating net able to provide the companies of the adjacent industrial area with winter heating and with the energy necessary for the technological cycles at lower costs compared with those currently borne. The economic analysis carried out on the possible profits coming from the sale of electric and thermal energy demonstrated how this opportunity will become an obligatory choice at the end of the period of facilitated payment for the energy given to the net. 
Table 8

Cash and investment flows: summary

\begin{tabular}{|c|c|c|c|}
\hline & $\frac{33 \%}{33 \%}$ & $\begin{array}{c}25 \% \text { Reduced MIX } \\
25 \% \\
50 \%\end{array}$ & $\begin{array}{c}\text { Intensive } M I X \\
10 \% \\
55 \%\end{array}$ \\
\hline Incomes ([EURO]) & & & \\
\hline Waste & 94,268 & 85,693 & 98,265 \\
\hline Electric energy & 147,795 & 147,795 & 147,795 \\
\hline $\begin{array}{l}\text { Outcomes ([EURO]) } \\
\text { Operation costs }\end{array}$ & 107,121 & 107,121 & 107,121 \\
\hline $\begin{array}{l}\text { Balance ([EURO]) } \\
\text { Monthly } \\
\text { Yearly }\end{array}$ & $\begin{array}{r}134,942 \\
1,619,310\end{array}$ & $\begin{array}{r}126,367 \\
1,516,405\end{array}$ & $\begin{array}{r}138,939 \\
1,667,272\end{array}$ \\
\hline $\begin{array}{l}\text { Investment ([EURO]) } \\
\text { Pay-back (years) }\end{array}$ & $\begin{array}{r}8,263,400 \\
5.10\end{array}$ & $\begin{array}{r}8,263,400 \\
5.45\end{array}$ & $\begin{array}{r}8,263,400 \\
4.96\end{array}$ \\
\hline
\end{tabular}

- The condenser dissipation fluid, which permits the closure of the steam cycle of the waste-to-energy plant, has a temperature of about $60{ }^{\circ} \mathrm{C}$. The district requires a large quantity of dried wood (180,000 ton/year) for chair manufacturing. At present, this quantity is obtained thanks to the use of small cell plants fed with traditional fuel, where the exit to ambient temperature is brought to $40-45^{\circ} \mathrm{C}$. Then the dissipation fluid can be exploited to feed the exchange section of a drying plant, by passing from the existing dissipation system in the evaporative tower to an air one. The carrying out of this project would mean, for the industrial district, the availability of a quantity of exsiccated wood at energetic null cost corresponding to $23 \%$ of the overall needs, with a centralized management of the raw-material provisions. The district would therefore, be able to exercise a far stronger contractual power towards the suppliers, and it would represent, as well, an intermediate stocking point close to the manufacturers with optimized inventory management possibility in the entire district.

- The combustion products $\left(35,000 \mathrm{Nm}^{3} / \mathrm{h}\right)$, with the enthalpic residual at $180{ }^{\circ} \mathrm{C}$, are generally dispersed in the atmosphere. This resource could meet the demand for heat to guarantee the cultivation temperature in winter months of a potential greenhouse for the production of tropical plants, to be built in the immediate proximity to the waste-to-energy plant. The innovative aspect, besides the water exchanger net for the recovery of the flue-gas enthalpic content, consists in putting directly into the greenhouse a small part of the combustion products $\left(3000 \mathrm{Nm}^{3} / \mathrm{h}\right)$. These will be first properly diluted with external air $\left(67000 \mathrm{Nm}^{3} / \mathrm{h}\right)$ and afterwards filtered in an algae biological digester in order to achieve the "carbonic manuring" thanks to their provision of $\mathrm{CO}_{2}$ [17], thus increasing the greenhouse productivity. The research is now focusing on the individualisation of the single most resistant algae species for building the above mentioned filter. 
The waste-to-energy plant, therefore, puts itself as the center of an integrated system which is able to meet the numerous needs of the district, thanks to which the charge of the waste disposal is transformed into a real competitive force for the single firms that would incur decidedly lower costs for the provision of important productive factors.

\section{Conclusions}

The purpose of the present work was to remark on the advisability of considering the industrial districts as particular aspects of the Italian industrial field, for which ideal engineering plant solutions have to be found able to overcome the innate weakness as of the single small firms as a result of collective actions. The homogeneity of these firm's problems and needs makes it possible to project plants operating for the whole district, which on the one hand could exploit evident economies of scale, and on the other could catalize the need for technological innovation that cannot be fulfilled by the single units because of their poor resource availability. Service facilities can thus become a real source of competitive advantage for the district with respect to its competitors. In this area, the university can play a privileged part thanks both to it institutionally being fit to act as a bonding agent among the parties, and to its being promoter of the scientific and technological innovation, which can be usefully applied to the local reality in which it operates.

The waste-to-energy plant for the woodworking waste which has been described in this study and is currently under test, represents a concrete example of the university-territory synergies. It not only successfully and efficiently answers the primary requirements of district waste disposal at reduced costs, but also employs innovative solutions and acts as a real laboratory of applied research. It can also be considered as the first step towards the creation of an integrated energy system able to transform the waste materials from an expense to a resource for the entire district.

\section{References}

[1] Haltiner EW. Better waste-to-energy plant for Amsterdam. MPS, September 1990. p. 65-69.

[2] Pirson R, Bracker GP. The GAVI Wijster 735.000 t/a waste to energy plant. MPS, November 1994. p. $57-64$.

[3] Ramsgard-Nielsen C, Sonderborg CHP plant burns gas and refuse. MPS, September 1994. p. 47-51.

[4] Haneda H. Efficiency improvement options for municipal waste-fired power generation-recent development activities in Japan: a rewiew. Proc Instn Mec Engrs 1995;A(209):89-100.

[5] Floreani M, Nardin G, Pinamonti P., Analysis of power from waste possibilities in the chair industrial district. Proceedings of the 2nd International Symposium on Incineration and Flue Gas Tratment Technologies, Sheffield, UK, 4-6 July 1999.

[6] Nardin G, Floreani M. Determination of the indicators of performance which characterize the plants for the energy conversion of the waste. Proceedings of the 7th International Conference on Power Engineering, Maribor, SLO, 12-14 May 1998.

[7] Meneghetti A, Nardin G. Plant location based on air-quality assurance. In: Muffatto M, Pawar S, editors. Proceedings of the 4th International Symposium on Logistics. Padua, Italy: SGE, 1999. 
[8] Baukal CE. Oxygen-enhanced combustion. Air Products and Chemicals, Inc. Allentown, PA: CRC Press LLC, 1998.

[9] Scutter J, Ostlund C, Meyer W. Techniques for $\mathrm{NO}_{x}$ reduction from MSW combustion plant. Proceedings of the 2nd International Symposium on Incineration and Flue Gas Treatment Technology, Sheffield, UK, 4-6 July 1999.

[10] Stoffel B, Riccius O. Low-NO $\mathrm{NO}_{x}$ incineration of municipal solid waste in grate systems. Proceedings of the 2nd International Symposium on Incineration and Flue Gas Treatment Technology, Sheffield, UK, 4-6 July 1999.

[11] Jansson S, Flue gas treatment for incineration processes that will meet the highest standards for the next millenium. Proceedings of the 2nd International Symposium on Incineration and Flue-Gas Treatment Technologies, Sheffield, UK, 4-6 July 1999.

[12] Leclaire T. Comparison of different treatment methods for residues of MSW incineration with respect to their ecological impacts. Proceedings of the 2nd International Symposium on Incineration and Flue-Gas Treatment Technologies, Sheffield, UK, 4-6 July 1999.

[13] National Patent No. UD99A000121. Torre di reazione per l'abbattimento di inquinanti in gas combusti, con preseparazione ciclonica delle polveri aerodisperse. Date: 01/07/1999, Validity: 20 years, Country: Italy, Owner: GEM s.r.l., Inventors: F. Giust and G. Nardin.

[14] Mohammadi B, Pironneau O. Analysis of the K-epsilon turbulence model. Masson, 1994.

[15] Franceschi F, Meneghetti A, Nardin G. Design and optimization of a prototype of a reaction tower with a semicyclone pre-separator. Proceedings of ANIMP Conference, Ischia, Italy, 21-22 October 1999 [in Italian].

[16] Meneghetti A, Nardin G, Rocco A. Integrated energy system on duty in an industrial district. Proceedings of ANIMP Conference, Trieste, October 2000 [in Italian].

[17] Di Bernardo E, Meneghetti A, Nardin G. Analysis of the technical-economic opportunity for the integration of waste-to-energy plants and greenhouses. Proceedings of ANIMP Conference, Trieste, Italy, October 2000 [in Italian]. 